\title{
Judith Husband: 'It's surprising what we can actually live without, other than air, water and food'
}

Please send any ideas for feature articles for consideration to:

Ruth Doherty,

Managing Editor,

British Dental Journal

The Macmillan Building,

4-6 Crinan Street,

London,

N1 9XW

Email: r.doherty@nature.com

Judith Husband speaks to the BDJ about current challenges facing dentistry, the new BDA PEC and her love of social media site Twitter. The only catch is she has accepted the challenge issued by interviewer and fellow Twitter enthusiast Laura Pacey of answering every question, in 140 characters or less. Follow on Twitter @Judith_Husband and @The_BDJ

What inspired you to

become a dentist?

Originally the science and wide range of subjects covered in the undergrad programme; also working with people and having my own business.

\section{What attracted you to prison dentistry?}

Luck: my principal had contracts, gained an additional one and offered it to me. I discovered I was good at it and enjoyed the challenge.

\section{What is the hardest thing about delivering oral healthcare in prisons?}

The current NHS reforms and associated changes in commissioning are leading to confusion and instability. It's impossible to plan long term.

\section{What is your favourite part of the working week?}

To be honest - Friday (as long as I'm not working at the weekend). I love dentistry but also enjoy time with friends and loved ones.

\section{Is there a lot of support for} prison dentists?

It varies across regions, commissioners and providers. Some like me are GDS, others salaried or corporates. In short, not at present.

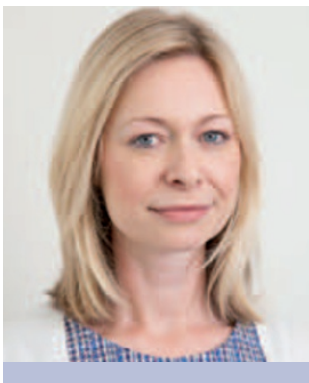

Judith Husband is a clinical dentist working in secure setting dental care, in addition to various roles in the BDA. Judith currently works in Bullingdon Prison, Oxfordshire, as well as providing service reviews and design for dental care in secure environments. She has been a Non-Executive Director of the BDA since 2006 and previously served as Deputy Chair of the Executive Board and Chair of Education and Standards Committee. Following restructuring of the BDA in Spring 2012, Judith is now elected to the Principle Executive Committee, which aims to focus upon governance and the strategic direction of the BDA. She is Chair of Audit Committee and also chairs the newly formed Education, Ethics and the Dental Team Committee. She graduated from Liverpool Dental School in 1997 before moving to Oxfordshire to work in general practice. She was President of the British Dental Students' Association initiating her zeal for dental politics and belief that involvement is key to supporting each other and our patients' health.

If you were justice minister is there anything you would change?

Review the relationship between NHS and prison; seems there's a disconnect now. Would also change drug laws - many need treatment not jail.

\section{What are the biggest challenges facing dental education in the UK today?}

The many providers and primary registerable qualifications quality assured by GDC - often hard to differentiate and make informed decisions.

Do you think there will be enough dental foundation training posts for students graduating this year?

DF1 places will match the number of UK graduates but with open competition from across EU and overseas there's likely to be a shortfall.
What is involved in being part of the BDA Principal Executive Committee (PEC)?

Identifying needs, supporting and representing members. Ensuring BDA is financially healthy for the future. Lots of reading and much more!

\section{What are you most excited about achieving through PEC?}

For many years we've known 21st century dentists and dentistry are very different - the BDA needed to change. Now we have taken that step.

What do you think is the best thing about the new BDA membership offering?

Choice and fairness. We're not all the same. Membership should be fair and accessible to all dentists and offer support to all dentists. 


\section{What has been the highlight of your career to date?}

Nothing has come close to the absolute relief and joy of seeing my name on the finals list of successful candidates.

Would you support a ban on fizzy drinks and sweets for children?

Not an outright ban; draconian prohibition doesn't work. Some form of additional taxation with investment into education and prevention yes.

If there could be a new miracle dental material what would you like it to fix?

That's really difficult. Oral cancer has the biggest impact but periodontal disease is most common. Can I choose both?

\section{Which famous person would you} like as a dental patient?

I've had enough 'infamous' patients over the years!

\section{If you weren't a dentist what would you do?}

No idea. It's been my plan from the age of 13. Rather fancy a dress shop on a bad day!
How useful do you find social media?

Useful or just enjoyable? It's a part of my life and often makes me smile - especially with the Twitter dental community.

Does social media play a role in dentistry?

It can on many levels. Fundamentally there has to be a commitment and clear plan of how to engage if it's being used on a commercial level.

\section{What do you like most about Twitter?}

Can exchange ideas and inform wide, varied groups in real time. Powerful and inclusive; enables relationship building and understanding.

\section{Could you get by without your phone?}

Absolutely (as long as there is a computer!). Phones aren’t permitted in prison.

\section{If you had to choose:}

Twitter or Facebook?

You have to ask? Facebook is too slow and sadly commercial now for my personal use.

\section{Hypnosis or general anaesthesia?}

Hypnosis. General anaesthetics should be avoided where reasonably possible.

\section{Eating out or eating in?}

At the weekend: eating out at a good restaurant. On a weekday: I prefer to cook and eat in at home.

\section{What three things could you not live without?}

Having met people who have suffered great hardship it's surprising what we can actually live without other than air, water and food.

What do you like to do in your spare time (when you have any!)?

Spend time with the Old One* and Random Cat*, friends and loved ones. Life's short, our personal relationships matter and must be nurtured.

What is the best piece of advice you have ever received?

Be true to yourself.

*Old One: how Judith refers to her partner on her Twitter feed and Random Cat: what Judith calls her cat on Twitter. 